Article

\title{
Organization Mechanisms and Spatial Characteristics of Urban Collaborative Innovation Networks: A Case Study in Hangzhou, China
}

\author{
Nina Liu ${ }^{1,2, *}$, Jiwu Wang ${ }^{1}$ and Yan Song ${ }^{2}$ \\ 1 Department of Regional and Urban Planning, Zhejiang University, Hangzhou 310058, China; \\ wangjiwu@zju.edu.cn \\ 2 Department of Regional and Urban Planning, University of North Carolina at Chapel Hill, \\ Chapel Hill, NC 27514, USA; ys@email.unc.edu \\ * Correspondence: zjulnn@foxmail.com; Tel.: +1-(404)-200-2320
}

Received: 26 September 2019; Accepted: 24 October 2019; Published: 28 October 2019

\begin{abstract}
Promoting the development of collaborative innovation networks is crucial for cities to achieve sustainable innovation. Hangzhou was selected as a case study. Based on the cooperation patent data from 2000 to 2017, we examined the scale problem, calculated the topology, and analyzed the coordination mechanisms and spatial characteristics of the topology structure. The results show that in terms of the development trend, collaborative innovation is an important pathway for innovation, and multi-subject collaborative innovation is necessary. Collaborative innovation occurs between enterprises and between enterprises and universities. With regards to topological structure, we found "Zhejiang University as a center, other universities as cores", with the characteristics of diffusion development and fragmentation. In terms of spatial structure, we observed a networked spatial organization model with multiple centers, such as universities and industrial parks. A circle with a radius of five kilometers around a university was found to be an area of highly concentrated innovation subjects that are synergistically associated with universities. On this basis, the laws are summarized and suggestions are provided to support the research and practice of urban innovation spatial planning in China.
\end{abstract}

Keywords: innovation subject; topological structure; collaborative innovation network; social network analysis

\section{Introduction}

The United Nations World Commission on Environment and Development officially proposed a sustainable development model in the report Our Common Future in 1897. The model is complex involving population, resources, environment, the economy, and other natural and social factors [1]. All these factors are affected by innovation. Innovation has shown power to solve the severe survival problems faced by the development of human society. It has gradually emerged from a narrow focus of only pursuing high economic growth, transitioning to pursuing the sustainable and harmonious development of nature, the economy, and society. Innovation is a necessary condition for sustainable economic development, and an important means to solve the negative impacts produced by science and technology [2]. Therefore, we must realize the importance of the dialectical relationship of technological innovation as the driving force for sustainable development, and sustainable development must rely upon innovation.

As the largest developing country in the world today, China has a large population but lacks resources. A crude industrial production mode has led to the consumption of natural resources and the destruction of the ecological environment. People now realize that sustainable development is 
essential due to awareness of problems such as resource depletion, energy shortages, and deterioration of the ecological environment. Given this realization, the original mode of extensive expansion at the expense of the environment has slowed. To address the bottleneck of urban development and promote the new normal of the economy, cities must transition from factor- and investment-driven development to innovation-driven development [3].

The development of innovation activities requires innovation space, which is the clustering material form projection in urban physical space of innovation activities-a series of knowledge-based economic activities such as science and technology, research, and communication [4]. Yigitcanlar and Lonnqvist found through research on multiple cities that innovation space has significantly different development characteristics and laws to traditional urban space [5]. As the space carrier of innovation, the uniqueness of innovation space prevents the simply application of traditional urban spatial planning and management theory. Traditional incremental simple space production is not suitable for current social and economic innovation development. Innovation space is a spatial material carrier based on the innovation activity development mechanism. Studying the development law and organization mode of innovation space through the mechanism of the innovation process is necessary for spatial planning of innovation space.

Innovation activities have a special organization and development mechanism, and their spatial development law is different from the traditional urban function due to their complexity and flexibility [6]. Research showed that the development of innovation activities has experienced the evolution process of "technical promotion and demand-driven linear model—complex coupling and parallel mode-cooperative innovation network model" [7,8]. The network structure is the most effective organizational model for achieving collaborative innovation and development $[9,10]$. A collaborative innovation network that facilitates the flow of knowledge, information, and other elements between innovation entities can achieve huge innovation effect [11]. Therefore, the cultivation and development of the collaborative innovation network is the key development direction for achieving sustainable innovation development [12]. As a material space containing innovative activities, the innovation space has corresponding development laws and organizational characteristics. Studying the organizational characteristics and spatial structure of the urban collaborative innovation network is necessary to promote sustainable innovation and development in cities.

Collaborative networks are the current innovation development paradigm, and social network analysis (SNA) is an important, mature, and appropriate research method for researching this type of network. SNA is a quantitative analysis method developed by sociologists based on mathematical methods and graph theory that is used to measure and investigate the characteristics of each part of the social system and their relationship with each other within the form of a network [13]. This method incorporates a set of theories, methods, and techniques that represent the whole process of relational patterns and characteristics [14]. SNA perfects the traditional analysis method that considers the individual as the research object, paying attention to the relationship between individuals and explaining individual behavior from the perspective of the group [15]. As a unique method of analyzing group relationship networks in sociology, SNA can be used to establish a model of the relationships among various innovation subjects in the collaborative network, and discover the relationships that describe the evolution characteristics of the collaborative network and the law of urban innovation collaborative network development. SNA has been used to study the innovation connections between cities at the macro scale, whereas collaborative innovation networks within a city have not been studied. Urban-scale spatial planning is more operable than at the regional scale to achieve sustainable innovation, and more attention should be paid to research on the collaborative innovation networks within cities.

We think that (1) innovation is the driving force of sustainable development. The sustainable development of the urban economy must shift from resource- to innovation-driven development. (2) The cultivation and development of collaborative innovation networks is the key development direction for achieving sustainable innovation and development. (3) SNA can effectively and 
scientifically describe the structural characteristics and development laws of urban collaborative networks. Patent data reflects effective innovation output, and the research on collaborative innovation networks using cooperative patents has been widely recognized by scholars. Innovation activities require innovation space, and the development of innovation space can promote innovation. The city is the basic and most important unit that can effectively implement innovation development policies and plans. It is important to conduct research on collaborative innovation networks and their spatial characteristics on the urban scale based on the inherent coordination of innovation activities. However, research is lacking on collaborative innovation networks within cities. Therefore, based on patent data, we applied the social network method to empirically study the development law of the structural characteristics of a city's collaborative innovation network, explore the internal relationship of urban innovation activities and its spatial laws, and then implement spatial planning. Our findings have important theoretical and practical significance for promoting the transition of the dynamic mechanism of urban development and achieving sustainable development.

The remainder of this article is structured as follows: Section 2 provides a literature review; Section 3 describes the research method and data; Section 4 outlines observations of the overall development process, trends, problems, and evolution of the collaborative innovation output of the city, and provides a calculation of the topology structure and spatial structure characteristics of the collaborative innovation network; and Section 5 includes our discussion, conclusions, and recommendations.

\section{Literature Review}

Innovation is a system, and the cohesion between the various innovation subjects in the system determines the innovation efficiency of the system. According to the theory of innovation, Schumpeter stated that innovation is a reorganization of the elements linked to socio-economic transformation and development, and is different from the development paradigm of the industrial economy [16]. Based on the characteristics of the innovation development paradigm, since the concept of the innovation system was first proposed by Lundvall [17], different scholars have studied the functional structure and dynamic mechanism of innovation development from a system perspective, and proposed that the innovation model should shift from focusing on the composition of elements to the association of elements. Etzkowitz and Leydesdorff [18] reported that universities, enterprises, and governments are the three major innovation factors, and the three interact to promote the spiral of innovation. The research space created by universities, research institutes, and enterprises transforms the elements of technological innovation into scientific and technological achievements, and enterprises develop applications and extension technologies on the core technologies absorbed. Adner and Kapoor [19] considered the innovation system as the coordination and symbiosis system of the resources of innovation, and stated that the collaboration and integration of the government, industry, and research is indispensable to innovation. The coordination between the various innovation subjects is the basic functioning mechanism and development driving force of the innovation system.

A collaborative innovation network is an effective organizational model for achieving sustainable innovation. With the integration of innovation resources and the cohesion of behavioral actors, the innovation process has experienced a simple linear technology-driven mode, linear market-driven mode, technology-market interaction mode, system integration mode, and collaborative network mode $[7,8]$. The innovation model development has become a multi-systematic network process that combines multiple factors. Freeman [20] stated that the contribution of the network to the role of innovation is a relatively new area of research, and the formation and the network emerges in response to organizations' need for knowledge. Jacobides and Billinger [21] thought that the innovation process no longer only occurs within enterprise boundaries or in a single industry, but is increasingly distributed in complementary network behaviors formed by resource differences. Ritter and Gemunden [22] showed that the companies that have close relationships with customers, suppliers, research institutions, and competitors are more likely to have higher product and process innovation success. Xie et al. [23] considered collaborative innovation networks as an effective framework to enable knowledge transfer 
between firms, and their findings revealed that the network size, network tie-strength, and network centrality determine the level of knowledge transfer performance. The innovation network emphasizes that the innovation subjects (including enterprises, universities, research institutions, intermediary organizations, and governments) implement the transmission of explicit or tacit knowledge through formal or informal institutional arrangements in the network for collaborative innovation [24,25].

Research on innovation networks is more consistently focusing on revealing their characteristics. People have begun to pay attention to how space matters in collaboration innovation on the macro scale. Li et al. [26] examined the topological and spatial features of urban innovation networks in China, and analyzed the evolution of scientific knowledge networks (SKNs) and technological knowledge networks (TKNs) with published papers and applied patents in the biotechnology field from 2000 to 2012. Lifener and Hennemann [27] analyzed the spatial configurations of knowledge networks and their overlap with spatial concentrations, such as urban agglomerations, and proposed a type of spatial concentrations in knowledge networks. Peschl and Thomas [28] proposed that space is important for collaborative innovation networks, enabling a more suitable approach to innovation. Space can be designed so that it enables and facilitates processes of collaborative knowledge creation and innovation. Cohen et al. [29] noted the increasing role of cities as drivers for innovation and entrepreneurship, and framed the innovation space as being cultivated by proactive cities. At the macro scale, research on collaborative innovation networks is gradually being conducted. Taking the Yangze River Delta urban agglomeration as the study object, Zhou et al. [30] analyzed the innovation network structure and measured the innovation network statutes based on cooperative patents.

Most studies characterized collaborative innovation networks with innovative outputs. Hoekman et al. [31] analyzed inter-regional research collaboration as measured by scientific publications and patents with multiple addresses, covering 1316 regions in 29 European countries. To study the structure and evolution of the global technological collaboration network, De Prato and Nepelski [32] used the patent-based data of international co-inventions and applied network analysis. The use of patent data to observe and analyze the organizational mechanism and spatial development characteristics of innovation activities has become a more common research strategy [33,34]. Patent data reflects effective innovation output, and the reliability of the distribution characteristics and development laws of innovation activities based on patent data has been verified [35-37]. The research on collaborative innovation networks using cooperative patents has been widely recognized by scholars [38].

In terms of research methods, through a case study of Sophia-Antipolis in France, TerWal [39] investigated to what extent collective learning networks have emerged throughout the growth of the business park. Scherngell and $\mathrm{Hu}$ [40] investigated collaborative knowledge production in China from a regional perspective, illustrated by spatial patterns of research collaborations between 31 Chinese regions, and estimated the impact of geographical, technological, and economic factors on the variation of cross-region collaboration activities within a negative binomial gravity model framework. Huallacháin and Lee [41] used social network analysis to explore the changing structures of collaborative systems of inter-metropolitan co-patenting in American biotechnology from 1979 to 2009 .

Through the literature review, we learned that scholars have used social networks, complex network analysis methods, and spatial interaction models (gravity, gravity models) to conduct considerable research using patents to measure the structural characteristics and evolution process of inter-regional innovation networks at the provincial, urban agglomeration, national, and even global spatial scales. Cultivating and building a collaborative innovation network is necessary for achieving sustainable innovation. However, studies are lacking about the intrinsic connection and spatial structure characteristics of collaborative innovation networks based on the collaboration of innovation activities at the urban scale. The macro-scale research results lack effective explanatory power for development on the urban scale, and the technical path of research on the urban scale is based on the spatial distribution of innovation activities [42]. Since researchers have not analyzed 
of the intrinsic link between innovation activities, this has affected the universal significance of the research conclusions.

Therefore, in the context of the implementation of innovative development in China's cities, we examined the collaborative innovation networks at the urban scale, looking at their organizational characteristics, and the spatial laws and planning development strategies at the level of urban material forms play an important role in the development of policy measures and spatial planning for urban innovation and development. Research on collaborative innovation networks on the region scale has been conducted, whereas research on the urban scale is absent. This study fills the gap in research on collaborative innovation networks at the relatively microscopic urban scale. We not only explain the collaborative connection mechanism from the perspective of topological structure, but also analyze the spatial distribution characteristics of collaborative innovation networks within a city. This research could help support the planning and construction of innovation space.

\section{Research Method and Data}

\subsection{Research Objective}

A city is an important spatial carrier for innovation activities. The cultivation and development of collaborative innovation networks is key to improving innovation efficiency and achieving the sustainable development of an innovation economy. Our research objective was to provide a spatial measure of the healthy development of urban collaborative innovation networks through research on the organization mechanism and spatial characteristics of urban collaborative innovation networks, which can be used to improve the efficiency of urban innovation and development.

To realize this objective, we: (1) analyzed the growth of cooperative patent data; observed the overall development process, trends, and problems of the collaborative innovation output of the city; and identified the composition of innovation subjects and the main relationships. (2) We used SNA to calculate collaborative innovation relationships to analyze the topology structure of the collaborative innovation network to depict the organization mechanism and further explain the correlation between the innovation network organization structure and coordinate innovation output. (3) The spatial structure characteristics of the collaborative innovation network were calculated using ArcMap10 (ESRI, Genelux, CA, USA, 2010). We proposed spatial development rules for the urban collaborative innovation network.

\subsection{Research Object}

Hangzhou, which is a typical and representative city in the field of innovation and development in China, was selected as the study object. The specific scope included: Xihu District, Shangcheng District, Xiacheng District, Gongshu District, Jianggan District, Binjiang District, Xiaoshan District, Yuhang District, and Fuyang District, including a total of 123 towns.

\subsection{Data Collection and Cleaning}

First, we collected patent application data from the State Intellectual Property Office of China for Hangzhou City from 2000 to 2017 were collected, totaling 406,565 data points.

We obtained cooperation information through data cleaning. The individual application subjects lacking spatial location information were removed, and the patent data from single application subjects were further removed, for a final total of 18,746 cooperative patent data points. The cooperation patent application data of two or more entities were using the two-two crossover, and 32,526 partnerships were identified.

According to the spatial location information, the cooperation relationship data occurring inside the city were obtained. The Amap (Amap, Beijing, China, 2010) and ArcMap10 (ESRI, Genelux, CA, USA, 2010) were used to spatially locate the coordinate information of the cooperative patent 
application subjects, and 20,225 partnerships that were created in Hangzhou were screened out to observe and analyze the collaborative innovation network structure of the city.

\subsection{Research Method}

The SNA method and UCINET6 (UCI, Irvine, CA, USA, 2008) were used to calculate and analyze the overall network structure and internal structural characteristics of the collaborative innovation relationships from the aspects of the overall network structure, sub-group composition, and network centrality. UCINET6 (UCI, Irvine, California, USA, 2008) and ArcMap10 (ESRI, Genelux, California, USA, 2010) were used to visually analyze the topology structure and the spatial distribution of the collaborative innovation network.

\subsubsection{Analysis of the Overall Structure of the Collaborative Innovation Network}

Indicators of the network center index, network density, and average distance were used to measure and analyze the overall structure of the collaborative innovation network. The network center index can be used to measure the extent to which an entire collaborative innovation network is concentrated toward a center. Network density refers to the ratio of the total number of contacts existing in the collaborative innovation network to the total number of possible contacts. The denser the network, the closer the relationship between collaborative innovation entities. The average distance refers to the number of nodes that any two innovative entities in the network need to produce collaborative innovation. The larger the average distance, the more difficult the creation of collaborative innovation among the innovation subjects [13].

\subsubsection{Analysis of the Centrality of the Collaborative Innovation Network}

The measure of network centrality can be used to analyze the inherent structural features of the collaborative innovation network from the perspective of the system structure. Specific indicators include the degree centrality and betweenness centrality of the node. The degree centrality of the node is the total number of other nodes directly contacted, which reflects the importance of the node in the network. The betweenness centrality of a node is calculated as the fraction of shortest paths between node pairs that pass through the node of interest. Betweenness is a measure of the influence of a node over the spread of information throughout the network. The higher the betweenness centrality of the node, the more control over other nodes, and the more network resources that the node manipulates [43].

\subsubsection{Analysis of the Composition of Sub-Groups in the Collaborative Innovation Network}

A closer coordination exists between the innovation entities in the same sub-group, and the links between the sub-groups are relatively weak [43]. Through analyzing sub-population composition, the organization and aggregation characteristics of the collaborative innovation network can be studied from the perspective of the collaboration mechanism. Therefore, sub-group composition and network centrality provides important information for studying the internal structure and organizational characteristics of collaborative networks from different perspectives.

\section{Research Results}

\subsection{Analysis of the Growth Scale and Development Trend}

\subsubsection{Scale Growth Characteristics and Problems of Collaborative Innovation}

During 2000-2017 in Hangzhou, the calculation of the scale of cooperative patents in each year shows an overall trend of accelerating growth, characterized by distinctive stages. In the first stage (2000-2005), the growth rate of cooperative patents was relatively slow, with an average annual increase of 18.40 patents. The second stage (2006-2010) showed a steady and rapid growth, with an average 
annual increase of 241.25 patents. The third stage (2011-2017) showed high-volatility growth, with an average annual increase of 247.83 patents and with significant volatility and instability (Figure 1).

Although the quantity of cooperative patents has shown overall growth overall, the proportion out of all patents remained low. Especially more recently, the growth trend of cooperative patents has not only shown significant instability, but also a trend of a relative growth rate that is lower than for single-subject patents, and a decline in their proportion.

According to the above calculation and analysis, the collaboration innovation output of Hangzhou has experienced problems with unstable development, a slower relative growth rate, and a decline in the overall proportion of patents, which will negatively impact its long-term and sustainable innovation development.

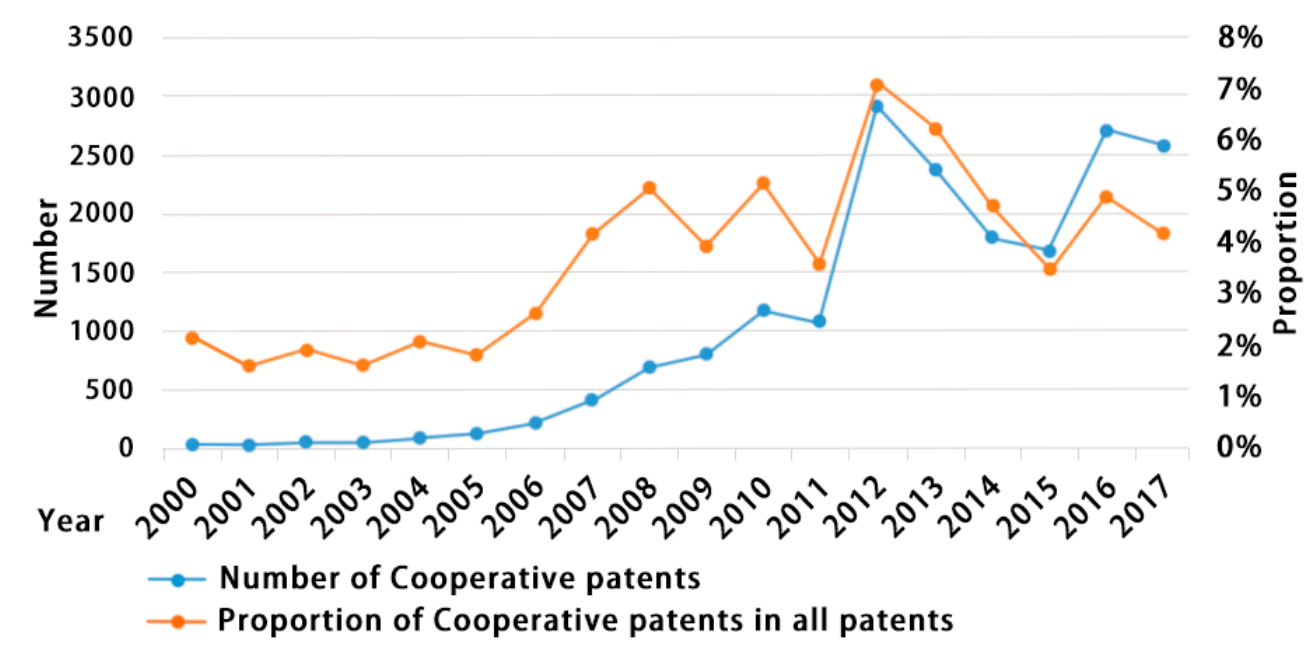

Figure 1. Patent cooperation and ratios in Hangzhou city, China from 2000 to 2017.

\subsubsection{Evolution Characteristics of Innovation Subjects in the Collaborative Innovation Network}

The development trend of the multi-subjects of collaborative innovation was obvious. The collation and calculation of innovation subjects in the network showed that the subjects include four types: enterprises, universities, scientific research institutions, and government departments. The number of innovation subjects and the cooperative relationships increased significantly during 2000-2017 (Figures 2 and 3).

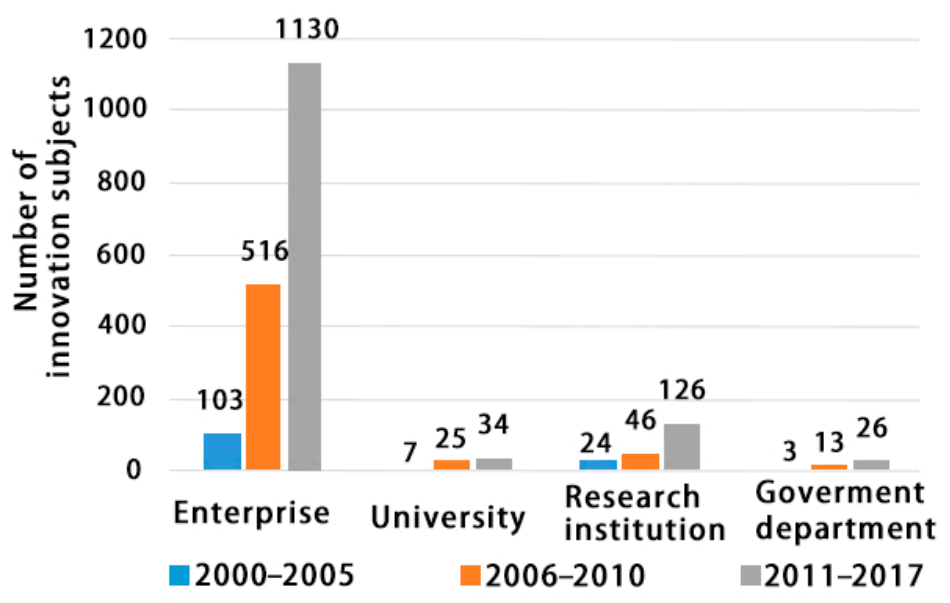

Figure 2. Quantity of innovation subjects. 


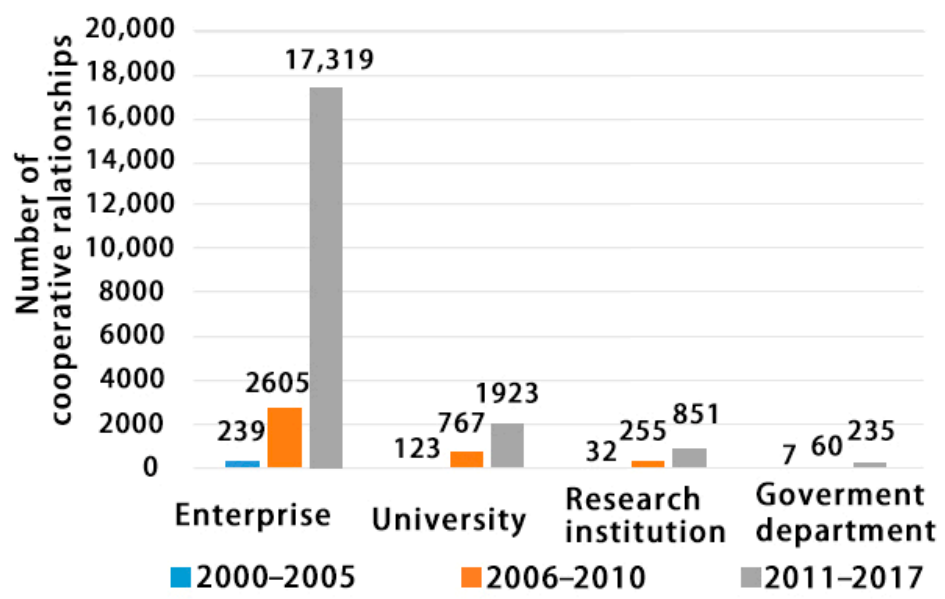

Figure 3. Quantity of cooperative relationships of innovation subjects.

Of the subject types, there were the most enterprises, and the innovation ability of universities was the strongest. Under the trend of multi-subject collaborative innovation, the number of enterprises and cooperative relationships in which they were involved were the largest and grew the fastest compared with the other subjects. In terms of average participation (Table 1), enterprises were increasingly active in collaboration innovation. Generally, the average participation of enterprises, research institutions, and government departments was still much lower than that of universities; that is, universities were the most active subjects with the strongest innovation ability in the collaborative innovation network. In terms of cooperation type (Table 2), the cooperation amongst enterprises and the cooperation between enterprises and universities were the most important collaborative innovation types. The cooperation between enterprises was the largest and grew fastest.

Table 1. Average participation of different innovative subjects (2000-2017).

\begin{tabular}{ccccc}
\hline Stage & Enterprises & Universities & Research Institutions & Government Departments \\
\hline $2000-2005$ & 2.33 & 17.57 & 1.32 & 2.18 \\
$2006-2010$ & 5.05 & 30.70 & 5.54 & 4.59 \\
$2011-2017$ & 15.33 & 56.55 & 6.75 & 9.03 \\
\hline
\end{tabular}

Note: Average participation is the ratio of the number of cooperative relationships in which one type innovation subject is involved to the number of the subjects, which can reflect the innovation ability of various innovation subjects.

Table 2. Form of partnerships between innovation subjects (2000-2017).

\begin{tabular}{cccccc}
\hline \multirow{2}{*}{ Stage } & $\begin{array}{c}\text { Total No. of Cooperation } \\
\text { Relationships }\end{array}$ & \multicolumn{2}{c}{$\begin{array}{c}\text { Cooperation Relationships } \\
\text { between Enterprises }\end{array}$} & $\begin{array}{c}\text { Cooperation Relationships between } \\
\text { Enterprises and Universities }\end{array}$ \\
\cline { 3 - 6 } & & No. & Proportion & No. & Proportion \\
\hline $2000-2005$ & 258 & 106 & $41 \%$ & 109 & $42 \%$ \\
$2006-2010$ & 2751 & 1761 & $64 \%$ & 652 & $24 \%$ \\
$2011-2017$ & 17,816 & 15,160 & $85 \%$ & 1482 & $8 \%$ \\
\hline
\end{tabular}

According to the calculation results, the increase in the collaborative innovation relationships between enterprises was huge, from 1761 in 2006-2010 to 15,160 in 2011-2017. Simultaneously, the growth of annual average collaborative innovation output did not increase significantly, and showed volatility. This shows that the collaborative innovation between enterprises was inefficient and uncertain.

\subsection{Evolution of the Topology Structure of the Collaborative Innovation Network}

Collaborative innovation generally showed growth during the period of 2000 to 2017. However, more recently, growth has shown significant volatility and instability and a decline in the relative growth 
rate and proportion. Therefore, the organizational topology structure and evolution characteristics of the collaborative innovation network needed to be calculated and analyzed to explain the characteristics and problems of scale growth, and support the corresponding spatial law and space planning interventions.

\subsubsection{Overall Structural Characteristics of the Network}

Based on the cooperative relationship of collaborative innovation subjects, the corresponding relationship matrix was established. UCINET6 (UCI, Irvine, CA, USA, 2008) was used to calculate the network center potential, network density, and average distance, which can be used to depict the overall topology structure and help with understanding the overall development process and trend of the Hangzhou collaborative innovation network (Table 3). The calculation results showed that the network center index and network density declined during the whole period from 2000 to 2017, and the average distance continued to increase. This indicates that the collaborative innovation network had a loosening trend, and the connection strength between innovation subjects was declining.

Table 3. Overall topology index of the collaborative innovation network.

\begin{tabular}{ccccccc}
\hline Stage & Center Index & $\begin{array}{c}\text { Average } \\
\text { Distance }\end{array}$ & Density & $\begin{array}{c}\text { No. of Innovation } \\
\text { Subjects }\end{array}$ & $\begin{array}{c}\text { Annual Average } \\
\text { Increase }\end{array}$ & Growth \\
\hline $2000-2005$ & 0.28 & 2.40 & 0.011 & 137 & 18.40 & Slow \\
$2006-2010$ & 0.29 & 3.26 & 0.003 & 600 & 241.25 & Rapid \\
$2011-2017$ & 0.16 & 3.82 & 0.002 & 1317 & 247.83 & Fluctuating \\
\hline
\end{tabular}

\subsubsection{Analysis of Network Centrality}

The degree centrality and betweenness centrality were calculated (Table 4). The results showed that with the development of the collaborative innovation network, universities have become the key factor within the collaborative innovation network structure of Hangzhou, and they control the circulation of network resources. The basic topological structure form was Zhejiang University as the center, other universities as cores, and enterprises as nodes of the collaborative innovation.

Table 4. Central structure index of the collaborative innovation network.

\begin{tabular}{|c|c|c|}
\hline Stage & Top Five Nodes in Degree Centrality & Top Five Nodes in Betweenness Centrality \\
\hline 2000-2005 & $\begin{array}{c}\text { Zhejiang University (39), } \\
\text { Zhejiang University of Technology (8), } \\
\text { Zhejiang Academy of Medical Sciences (4), } \\
\text { Hangzhou Saili Pharmaceutical Research } \\
\text { Institute Co. (4), } \\
\text { Zhejiang Dade Pharmaceutical Co. (4) }\end{array}$ & $\begin{array}{c}\text { Zhejiang University (13.91), } \\
\text { Zhejiang University of Technology (4.13), } \\
\text { Zhejiang Academy of Medical Sciences (2.15), } \\
\text { Zhejiang Lantian Environmental Protection High } \\
\text { Technology Co. (0.56), } \\
\text { Hangzhou Kangyuan Food Technology Co. (0.56) }\end{array}$ \\
\hline 2006-2010 & $\begin{array}{l}\text { Zhejiang University (173), } \\
\text { ZhejiangUniversity of Technology (50), } \\
\text { Zhejiang Sci-Tech University (25), } \\
\text { Wanxiang Company (13), } \\
\text { China Jilang University (11) }\end{array}$ & $\begin{array}{c}\text { Zhejiang University (27.57), } \\
\text { Zhejiang University of Technology (8.58), } \\
\text { Zhejiang Sci-Tech University (4.16), } \\
\text { China Jilang University (1.95), } \\
\text { Second Institute of Oceanography, State Oceanic } \\
\text { Administration (1.48) }\end{array}$ \\
\hline 2011-2017 & $\begin{array}{l}\text { Zhejiang University (209), } \\
\text { Zhejiang University of Technology (86), } \\
\text { Zhejiang University City College (66), } \\
\text { Zhejiang Sci-Tech Universit (62), } \\
\text { Zhejiang Electric Power Company (27) }\end{array}$ & $\begin{array}{c}\text { Zhejiang University (28.61), } \\
\text { Zhejiang University City College (8.31), } \\
\text { Zhejiang University of Technology (8.28), } \\
\text { Zhejiang Sci-Tech University (5.59), } \\
\text { China Jiliang University (2.71) }\end{array}$ \\
\hline
\end{tabular}

\subsubsection{Analysis of Sub-Groups of the Network}

UCINET6 (UCI, Irvine, CA, USA, 2008) was applied to visually analyze the sub-groups of the collaborative innovation network and each sub-group contained at least three innovation nodes (Figure 4). The results showed that the number of sub-groups was increasing rapidly (Table 5). 
According to the sub-group formation process, the structure of the network was characterized by fragmentation. As the largest collaboration innovation subject, enterprises had not formed a synergistic relationship with the center and cores of the collaboration innovation network, but rather formed relatively closed and small-scale cooperation sub-groups between enterprises. As a result, the collaboration innovation network of the city had the structural characteristics of diffusion and fragmentation.

\begin{tabular}{|c|c|c|c|}
\hline Stage & $2000-2005$ & $2006-2010$ & 2011-2017 \\
\hline $\begin{array}{l}\text { The largest } \\
\text { sub-group }\end{array}$ & 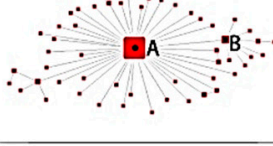 & 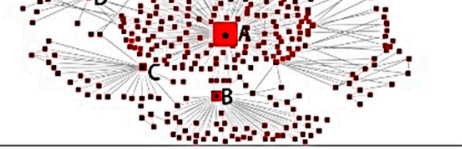 & $\therefore$ \\
\hline $\begin{array}{l}\text { Other } \\
\text { sub-groups }\end{array}$ & $\because \because \because \because:: \because \because$ & 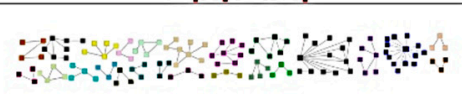 & 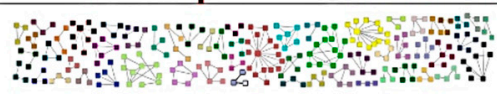 \\
\hline $\begin{array}{l}\text { Nodes outside } \\
\text { sub-groups }\end{array}$ & 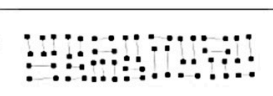 & 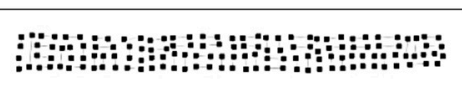 & 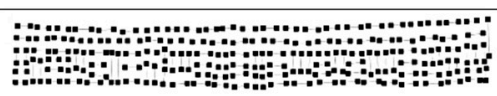 \\
\hline
\end{tabular}

Figure 4. The collaborative innovation network based on centrality topology.

Table 5. Sub-group index of the collaborative innovation network.

\begin{tabular}{cccc}
\hline Stage & No. of Sub-Groups & $\begin{array}{c}\text { No. of Nodes Contained } \\
\text { in Largest Sub-Group }\end{array}$ & $\begin{array}{c}\text { Proportion of Nodes Contained } \\
\text { in Largest Sub-Group }\end{array}$ \\
\hline $2000-2005$ & 7 & 53 & $38.69 \%$ \\
$2006-2010$ & 25 & 332 & $55.33 \%$ \\
$2011-2017$ & 59 & 787 & $59.76 \%$ \\
\hline
\end{tabular}

\subsection{Analysis of the Spatial Structure of the Collaborative Innovation Network}

The aim of the topological analysis was to abstract spatial elements into points and lines to quantify the coordination between urban innovation subjects. Spatial structure analysis can reflect the actual structural characteristics of the topological structure in geospatial terms. Only by transforming the network topology analysis into concrete spatial structure analysis the spatial development laws and characteristics of urban collaborative innovation networks be discovered.

According to the research, the urban collaborative innovation network does not have a horizontal and uniform network structure, but has certain hierarchical characteristics: a collaborative center (Zhejiang University), collaborative cores (Zhejiang University of Technology and other universities), and innovation nodes (general innovation subjects, mainly enterprises). Universities have absolute control over the structure and factor flow of the collaborative innovation network in Hangzhou. Therefore, according to the 2011-2017 cooperation results, ArcMap10 (ESRI, Genelux, CA, USA, 2010) was used to spatially visualize the collaborative innovation relationships in which universities are involved and other collaborative innovation relationships in which general innovation subjects are involved to grasp the spatial structure of the collaborative innovation network.

\subsubsection{Spatial Distribution Characteristics of Universities' Collaboration Innovation Relationships}

Universities are the important center and cores of the collaboration innovation network, and the relationships in which they are involved cover the main built-up area of the city (Figure 5). The area within a radius of five kilometers from the center of a university contains a high concentration of innovation subjects that have synergistic relationships with the university, such as Zhejiang University Yuquan Campus, Zhejiang University of Technology, Zhejiang Sci-Tech University, and China Jilang University. The innovation subjects with collaborative relationships with universities were characterized 
by spatial agglomeration development in urban central areas and industrial parks, and a scattered distribution in other areas. The universities had different spatial synergistic relationship orientations (Table 6).
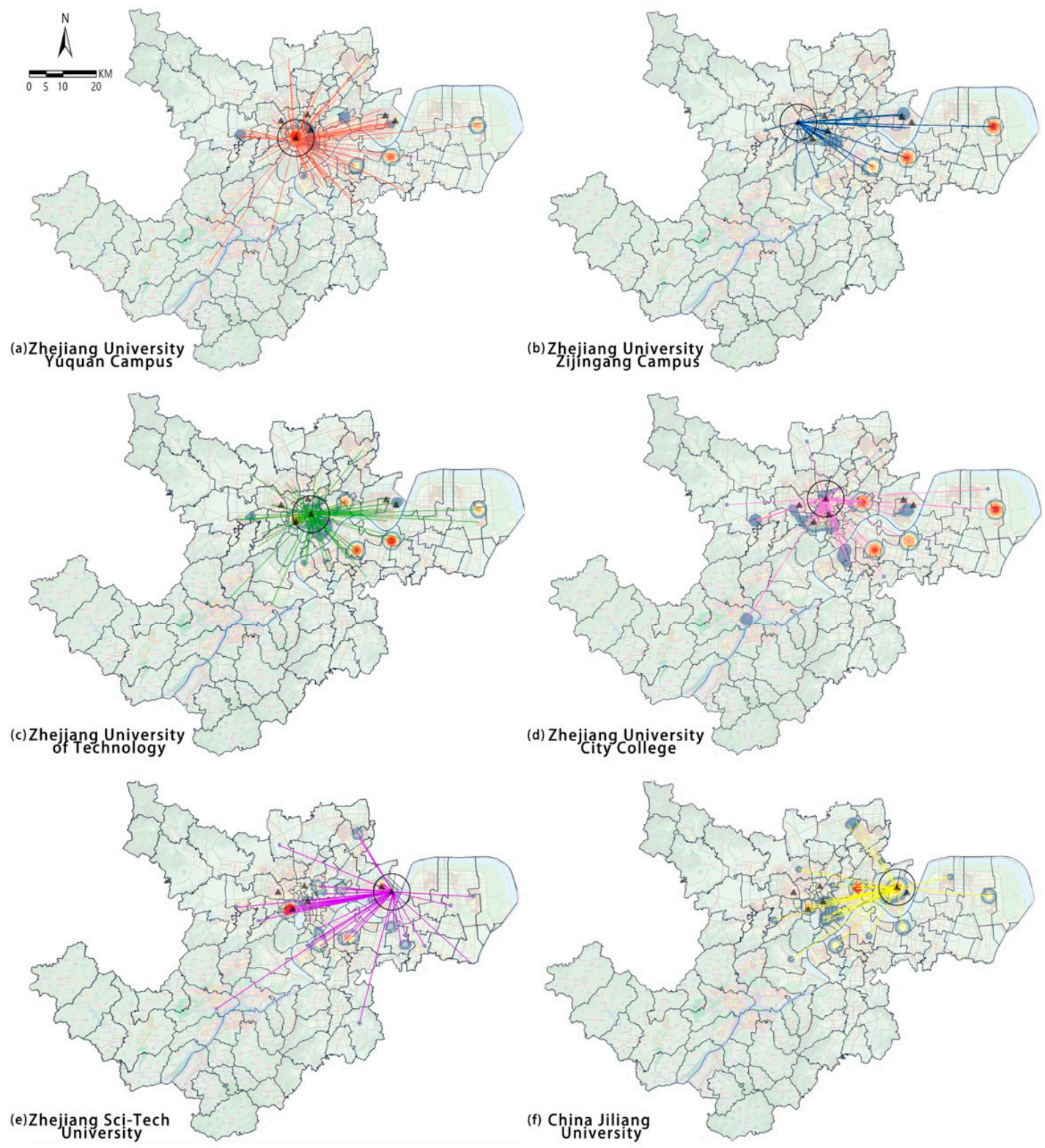

$\Delta$ Universit

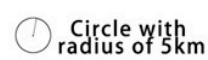
Collaborative innovation

High Density estimation of subjects

Figure 5. Spatial distribution of partnerships of the collaboration center and cores.

Table 6. The main distribution areas of innovation subjects related to universities.

\begin{tabular}{cc}
\hline University & $\begin{array}{c}\text { Main Areas with Collaborative Innovation Relationships with } \\
\text { the University (According to the Size of the Density Estimation) }\end{array}$ \\
Zhejiang University Yuquan Campus & $\begin{array}{c}\text { South District of Xiaoshan Economic Development Zone, } \\
\text { Dajiangdong Industrial Cluster Area, Xiaoshan Economic } \\
\text { Development Zone, etc. }\end{array}$ \\
Zhejiang University Zijingang Campus & $\begin{array}{c}\text { Dajiangdong Industrial Cluster Area, Xiaoshan Economic } \\
\text { Development Zone, South District of Xiaoshan Economic } \\
\text { Development Zone, etc. }\end{array}$ \\
\hline
\end{tabular}


Table 6. Cont.

\begin{tabular}{cc}
\hline University & $\begin{array}{c}\text { Main Areas with Collaborative Innovation Relationships with } \\
\text { the University (According to the Size of the Density Estimation) }\end{array}$ \\
\hline Zhejiang University of Technology & $\begin{array}{c}\text { South District of Xiaoshan Economic Development Zone, Xiaoshan } \\
\text { Economic Development Zone, Zhejiang University Science Park, etc. } \\
\text { Zhejiang University City College } \\
\text { Zhejiangdong Industrial Cluster Area, Zhejiang University Science } \\
\text { and Technology Park, Xiaoshan Economic Development Zone, etc. } \\
\text { Downtown, South District of Xiaoshan Economic Development } \\
\text { China Jilang University }\end{array}$ \\
$\begin{array}{c}\text { Zone, National High-Tech Development Zone, etc. } \\
\text { Zhejiang University Science Park, Downtown, National High-tech } \\
\text { Development Zone, etc. }\end{array}$ \\
\hline
\end{tabular}

4.3.2. Spatial Distribution Characteristics of Other Collaboration Innovation Relationships of General Subjects

The general innovation subjects were mostly enterprises, and the spatial characteristics of the synergistic relationships in which they were involved showed that collaborative innovation relationships occurred among the main industrial parks in Hangzhou, such as Dajiangdong Industrial Cluster, Xiaoshan Economic Development Zone, Hangzhou National High-Tech in Binjiang District, and so on (Figure 6). Fewer collaborative relationships were found between enterprises in the same industrial agglomeration area. The contribution of enterprise agglomeration in the industrial parks to collaboration innovation was not obvious.

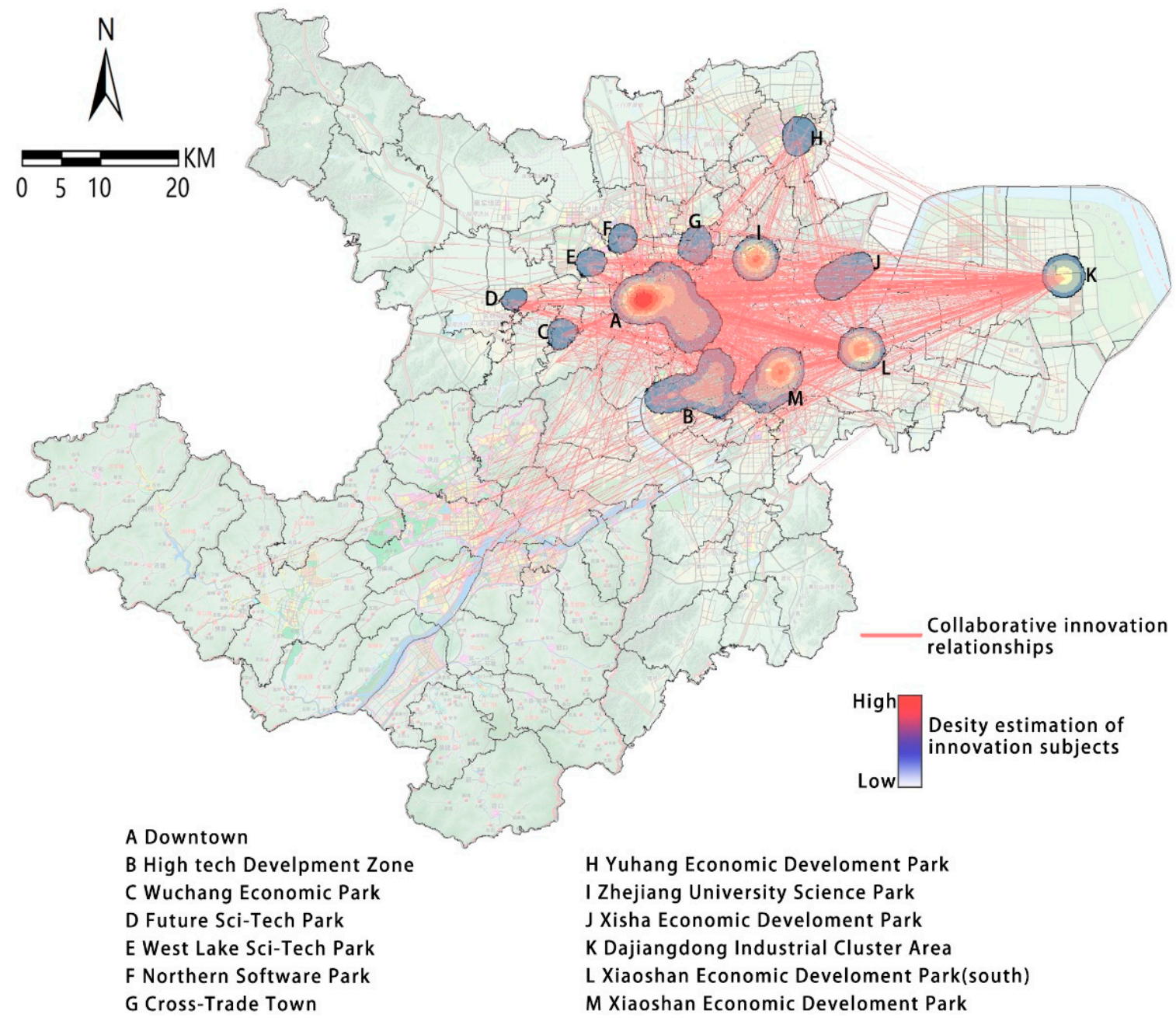

Figure 6. Spatial distribution of partnerships of general nodes. 


\section{Conclusions and Recommendations}

\subsection{Topology Structure of the Collaborative Innovation Network}

Universities and enterprises were the main subjects of collaborative innovation in the city. The collaborative relationships of the university-enterprise and enterprise-enterprise are the main connections in the city's collaborative innovation network. The intrinsic connection mechanism (topological relationship) of the network has an important influence on the growth of the urban collaborative innovation output. The relative proportion of university-enterprise relationships declined significantly, while the enterprise-enterprise relationships increased. This intensified the fragmentation of the collaborative innovation network. The fragmentation leaded to the slowdown of the innovation output growth and the instability of the growth process. It is important to improve the connectivity between the university-enterprise to improve collaborative innovation.

The topological structure of the collaborative innovation network within the city has multiple levels of overlapping features that can be divided into the largest sub-group, other sub-group, and outside sub-group. The largest group is driven by universities and composed of university-enterprise and enterprise-enterprise relationships. It is featured by a multi-center networked structure and constitutes the main body of the collaborative innovation network. The other sub-group and outside sub-group are mainly composed of enterprise-enterprise relationships, which are featured by a fragmented network structure.

In summary, the topology indicators of the collaborative innovation network reflect the different development characteristics of the three stages. From 2000 to 2005, the collaborative innovation network was characterized by high concentration and close connection (the network center potential was 0.28 , average distance was 2.40 , and the network density was 0.011 ). The collaborative innovation network included small-scale subjects coordinated closely with Zhejiang University as the collaborative center. The slow growth of the innovation output characterized the collaborative innovation development at this stage. From 2007 to 2010, the collaborative innovation relationship network tended to diffuse (the network center was 0.29 , the average distance increased to 3.26, and the network density dropped sharply to 0.003 ). It basically formed a collaborative innovation network structure with Zhejiang University as the collaborative innovation center, other universities as collaborative innovation cores, and enterprises as collaborative innovation nodes. The innovation output showed a trend of continuous rapid growth. From 2010 to 2017, the collaboration innovation network further diffused (the network center potential dropped to 0.16 , the average distance increased to 3.82 , and the network density dropped to 0.002). In addition to the collaborative innovation network structure with Zhejiang University as the center, other universities as cores, and enterprises as nodes, many sub-groups formed outside the main structure of the network. The majority of innovation subjects in these sub-groups were enterprises. Simultaneously, the average annual collaborative innovation output at this stage was 244.83 patents, which was almost the same as the 241.25 patents in the previous stage (2007-2010). The significant increase in sub-groups outside the main network structure minimally contributed to the growth of the innovation output, and led to the fragmentation of the network. Therefore, under the development trend of multi-subject collaboration innovation, it is necessary to optimize the collaborative innovation network structure and to promote the collaborative innovation between enterprises and universities, as well as between enterprises, to further enhance the innovation output. Under this linkage mechanism, a spatial plan is needed to adjust the structure of the collaborative innovation network to promote the optimization of the network from a spatial perspective, which could considerably contribute to the growth of innovation output. 


\subsection{Spatial Characteristics of the Collaborative Innovation Network and Recommendations}

\subsubsection{Spatial Characteristics of the Collaborative Innovation Network}

In terms of the spatial organization structure, traditional urban space develops in a circle-level model centered on the city's central business district. The traditional urban spatial organization model is no longer suitable for innovation given the flexibility and complexity of innovation development. Innovation subjects concentrate around universities and industrial parks, and collaborative innovation activities often occur between the clusters, increasing the strength of the spatial correlation among clusters. Therefore, the spatial distribution of urban collaborative innovation networks has multi-center and networked development trends and characteristics. Under the networked linkage mechanism, the spatial structure of the collaborative network is formed by small-scale spatial agglomeration and large-scale spatial connection.

In terms of the key space of the collaborative innovation network, according to the calculation results, universities have the strongest innovation ability, and their collaborative innovation with enterprises is one of the most important cooperation relationships. The collaborative innovation circle within a radius of five kilometers around a university is an area where innovation subjects synergistically related to the university were highly concentrated. Universities play an innovative role in the key areas and promote collaborative innovation. In the spatial layout of the Hangzhou collaborative innovation network, the areas surrounding Zhejiang University, Zijingang Campus, and Zhejiang University City College already had industrial clusters, such as Xihu Science and Technology Park and Cross-Trade Town, but the universities and industrial clusters have not established collaborative innovation relationships with each other. The areas surrounding these universities have not developed into collaborative innovation highland, and the function of these universities as cores has not been fully realized. Another key area for collaborative innovation is the downtown area, with the densely distributed enterprises. Downtown is important for improving the connectivity of the collaborative innovation network.

The calculation results also show three important spatial connections: university-industrial park, downtown-industrial park, and industrial park-industrial park. These spatial connections have no spatially similar distribution characteristics; that is, the intensity of spatial connection is not affected by spatial distance.

In terms of the impact factors, the spatial policy of urban innovation development is closely related to the aggregation of innovation subjects and significantly impacts the spatial structure of an urban collaboration innovation network. The planning and construction of urban fringe areas, such as college towns, campuses of universities, and economic development zones, have become important for the aggregation of innovation subjects and important nodes of the collaboration innovation network due to the concentration of talents and technology. The urban central area has a higher level of innovation agglomeration compared with fringe areas.

In terms of industrial agglomeration, the innovation subjects of the Hangzhou collaboration innovation network are concentrated in physical space, but with less collaboration innovation relationships between each other. The physical distance is close but the network distance is far. The agglomeration of innovation subjects is likely to be an important condition for promoting innovation, but it does not guarantee the agglomeration of innovation. Whether the agglomeration can promote innovation depends on the process of collaboration innovation among subjects.

\subsubsection{Recommendations}

In this study, we identified some of Hangzhou's collaborative innovation spatial characteristics, which is a representative innovative city in China. The optimization of the collaboration innovation network should shift from focusing on increasing the number of subjects to the construction of collaborative relationships between subjects. The contribution of increasing the number of innovation subjects simply to promote the scale of innovation output is no longer obvious. Spatial planning 
should be used as a method to optimize the network structure of collaboration innovation, which could promote the establishment of collaboration innovation relationships among subjects and promote innovation. Based on the spatial development characteristics of the collaborative innovation network, the following spatial planning recommendations were proposed:

(1) Overall, the collaborative innovation network has a multi-center networked spatial organization model. Therefore, according to the spatial characteristics of the network structure, attention should be paid to the spatial connection amongst universities and industrial parks in terms of transportation, guaranteeing the smooth flow of innovation resources such as talent, logistics, and information to promote collaborative innovation.

(2) Universities are collaborative innovation network centers. The closer a company is to the network center, the more favorable for the innovation output. The cooperation innovation with universities is the key path for enterprises in the sub-groups outside the main network structure to be embedded within the innovation network. The five-kilometer radius around a university is an important physical location for collaborative innovation. Therefore, the space surrounding universities should be updated and optimized, matching corresponding innovation spaces and creating a collaborative innovation circle around universities. Improving the school-enterprise cooperation mechanism is important for promoting the cooperation between universities and enterprises.

(3) Innovation subjects are highly concentrated in the downtown, which can provide a better urban environment than fringe areas and remote suburbs. Therefore, we should pay attention to the optimal use of downtown space. The widespread use of information and the Internet is changing the traditional spatial location of innovative companies, as well as changing the traditional path of promoting downtown renewal with businesses and business offices. The new trend of innovative enterprise agglomeration is a new path for the revival of downtown areas. The typical investment-driven feature is the formation of a central business district or a central activity zone, whereas being innovation-driven may encourage the formation of a central intelligence zone with innovation as its core activity in the downtown area.

(4) Industrial parks should allocate corresponding sharing service facilities according to the preference of innovative talent, and increase their informal communication opportunities. Enterprises can collaborate with each other by sharing service facilities. Enterprises in the same industry have homogeneous knowledge and can easily cooperate. Heterogeneous knowledge exchanges between enterprises from different industries could motivate innovation ideas. Therefore, the functional area planning of industrial parks should be guided by industry categories to form a spatial organization model with small agglomerations and large integration, to provide conditions for industrial cluster innovation and shift innovation elements from a simple space concentration to cluster innovation development.

In summary, our research objective was to study the organization mechanism and spatial structure characteristics of collaborative innovation networks on an urban-scale. Our findings fill the gap in research on urban scale of collaborative innovation networks. Based on the statistical data of collaborative innovation patents of 2000-2017 from Hangzhou, we analyzed the growth trend of innovation output, and SNA was used to visually analyze the topology structure of the collaborative innovation network. We also calculated and analyzed the spatial scale effect of the collaborative innovation network relationships and the spatial characteristics of the collaborative innovation network. We defined key areas and important spatial connections for collaborative innovation development. We explained the organization mechanism and spatial characteristics of urban collaborative innovation, and reviewed problems and strategies that may arise in the process of urban innovation development. The results and conclusions provide theoretical tools and measures for scientific formulations and the implementation of urban innovation development policies and plans. 


\subsection{Discussion}

This empirical research, with Hangzhou as an example, has international significance for other cities. In the era of the knowledge-based economy, innovation is the trend in urban development. The collaborative innovation network characterized by innovation patents has a multi-center structure. Knowledge production spaces such as universities and high-tech industrial parks have become nodes of the network. Promoting collaborative innovation among innovation subjects is the key to improving innovation efficiency. Universities are important knowledge creators in the innovation system and the core nodes of the network. Cooperation with universities is the key path to embed into the innovation network. Enterprises should pay more attention to innovative application development. We should promote the coordination between universities and enterprises, and build a scientific and technological innovation service platform to improve school-enterprise collaboration. The area surrounding the university is important for collaborative innovation and appropriate space and facilities should be provided. In the industrial park, a cooperation platform should be built to integrate resources, help enterprises find partners, and promote collaborative innovation among enterprises.

SNA is a relatively mature research method for analyzing social relationships. We used SNA to analyze the collaborative innovation relationships and spatial connections among innovation subjects, and to describe the evolution process of the collaborative innovation network within the city. SNA takes the innovation subject as the point and the connection between the subjects as the line. It provides a quantitative test tool for empirical research to objectively quantitatively analyze various relationships in the network. SNA can be used to characterize the overall structure of the network through the network-center index, network density, and average length, and to analyze individual behaviors though indicators such as the node center degree, intermediate center degree, and sub-group.

We selected the urban scale as the research scale and depicted the collaborative innovation network within the city in detail. However, there were some limitations to the study. The city's collaborative innovation network were multi-scale, cross-border collaborative innovation networks that had not been analyzed in the study and should be further researched in the future. In addition, cooperative patents were not the only aspect available to consider when measuring collaborative innovation. Future research should comprehensively consider various cooperation methods, such as cooperative studies and cooperative scientific research projects to fully reflect the development law of the urban collaborative innovation network.

Author Contributions: N.L. conceived the research and methodology, collected and cleaned all the data, and finished the calculation and analyzed the results; J.W. formed the policy recommendations; Y.S. revised the manuscript and approved the manuscript; N.L. and J.W. are responsible for future questions from readers as the corresponding authors.

Funding: This research was supported by the National Nature Science Foundation Project (51238011) and Zhejiang University New Urbanization Research Institute Foundation Project. The authors are grateful for the support of the National Nature Science Foundation and Zhejiang University. The contents of this paper are solely the responsibility of the authors and do not represent the official views of the institutes and funding agencies.

Conflicts of Interest: The authors declare no conflict of interest.

\section{References}

1. Brundtland, G.H. Our Common Future. World Commission on Environment and Development; United Nations: Brussel, Belgium, 1987.

2. Alm, A. Environment and technological innovation environment science and technology. Environ. Technol. Innov. 1992, 25, 1300.

3. Zhao, Y.; Bai, Y.X. Knowledge spillovers: A survey of the literature. Econ. Res. J. 2009, 1, 144-156.

4. Zeng, P.; Zeng, J.; Cai, L.W. Research on theoretical construction and spatial modality of urban innovation space. Archit. J. 2008, 8, 34-38.

5. Yigitcanlar, T.; Lonnqvist, A. Benchmarking knowledge-based urban development performance: Results from the international comparison of Helsinki. Cities 2013, 3, 357-369. [CrossRef] 
6. Wang, J.W.; Liu, N.N.; Zhang, Y.Q. Development mechanism and spatial strategy of innovation cluste. Planners 2017, 33, 42-48.

7. Rothwell, R. Successful industrial innovation: Critical factors for 1900s. RED Manag. 1992, 22, 221-239.

8. Duin, H.; Jaskov, J.; Hesmer, A.; Thoben, K.-D. Towards A Framework for Collaborative Innovation; Springer: Cambridge, MA, USA, 2008; pp. 193-204.

9. Bathelt, H.; Malmberg, A.; Maskell, P. Clusters and knowledge: Local buzz, global pipelines and the process of knowledge creation. Prog. Hum. Geogr. 2004, 28, 31-56. [CrossRef]

10. Bergenholtz, C.; Waldstrøm, C. Inter-organizational network studies: A literature review. Ind. Innov. 2011, 18, 539-562. [CrossRef]

11. Liu, L.; Xiang, L.L. A visual analysis on evolving rule and hotpots of research in innovation network. RED Manag. 2019, 31, 145-158.

12. Huang, H.X.; Chen, J. Collaborative innovation network mode within innovation ecosystem. Technol. Econ. 2016, 35, 31-37, 117.

13. Scott, J. Social network analysis. Sociology 1988, 22, 109-127. [CrossRef]

14. Borgatti, S.P.; Mehra, A.; Brass, D.J.; Labianca, G. Network analysis in the social science. Science 2009, 323, 892-895. [CrossRef] [PubMed]

15. Carrington, P.J.; Scott, J.; Wasserman, S. Models and Methods in Social Network Analysis; Cambridge University Press: New York, NY, USA, 2005.

16. Schumpeter, J.A. The Theory of Economic Development, 16th ed.; Transaction Publishers: Piscataway, NJ, USA, 2012; pp. 72-87.

17. Lundvall, B.A. Product Innovation and User-Producer Interaction; Industrial Development Research Series; Aalborg University Press: Aalborg, Denmark, 1985.

18. Etzkowitz, H.; Leydesdorff, L. Universities and the Global Knowledge Economy: A Triple Helix of University-Industry-Government Relations; Book of Abstracts; University of Amsterdam: Amsterdam, The Netherlands, 1997; p. 169.

19. Adner, R.; Kapoor, R. Value creation in innovation eco-systems: How the structure of technological interdependence affects firm performance in new technology generations. Strateg. Manag. J. 2010, 31, $306-333$. [CrossRef]

20. Freeman, C. Network of innovation: A synthesis of research issues. Res. Policy 1991, 20, 499-514. [CrossRef]

21. Jacobides, M.G.; Billinger, S. Designing the boundaries of the firm: From make, buy or ally to the dynamic benefit of vertical architecture. Organ. Sci. 2006, 17, 56-66. [CrossRef]

22. Ritter, T.; Gemunden, H.G. Network competence: Its impact on innovation success and its antecedents. J. Bus. Res. 2003, 56, 745-755. [CrossRef]

23. Xie, X.M.; Fang, L.X.; Zeng, S.X. Collaborative innovation network and knowledge transfer performance: A fsQCA approach. J. Bus. Res. 2016, 69, 5210-5215. [CrossRef]

24. Kapoor, R.; Lee, J.M. Coordinating and competing in eco system: How organization forms shape new technology investments. Strateg. Manag. J. 2013, 24, 274-296. [CrossRef]

25. Rowley, T.; Behrens, D.; Krackhardt, D. Redundant governance structures: AN analysis of structural and relational embeddedness in the steel and semiconductor industries. Strateg. Manag. J. 2000, 21, 369-386. [CrossRef]

26. Li, D.; Wei, Y.D.; Wang, T. Spatial and temporal evolution of urban innovation network in China. Habitat Int. 2015, 49, 484-496. [CrossRef]

27. Lifener, I.; Hennemann, S. Structural holes and new dimensions of distance: The spatial configuration of the scientific knowledge network of China's optical technology sector. Environ. Plan. A Econ. Space 2011, 43, 810-829. [CrossRef]

28. Peschl, M.F.; Thomas, F. Why space matters for collaborative innovation network. On designing enabling spaces for collaborative knowledge creation. J. Organ. Des. Eng. 2014, 3, 358-391. [CrossRef]

29. Cohen, B.; Almirall, E.; Chesbrough, H. The city as a lab: Open innovation meets the collaborative economy. Calif. Manag. Rev. 2016, 59, 5-13. [CrossRef]

30. Zhou, C.; Zeng, G.; Mi, Z.F.; Xian, G. The study of regional innovation network patterns: Evidence from the Yangtze River Delta Urban Agglomeration. Prog. Geogr. 2017, 36, 795-805.

31. Hoekman, J.; Frenken, K.; Van Oort, F. The geography of collaborative knowledge production in Europe. Ann. Reg. Sci. 2009, 43, 721-738. [CrossRef] 
32. De Prato, G.; Nepelski, D. Global technological collaboration network: Network analysis of international co-inventions. J. Technol. Transf. 2014, 39, 358-375. [CrossRef]

33. Lim, U. The spatial distribution of innovative activity in US metropolitan areas: Evidence from patent data. J. Reg. Anal. Policy 2003, 33, 97-98.

34. David, L.R. Technological Relatedness and Knowledge Space: Entry and exit of US cities from patent classes. Reg. Stud. 2015, 49, 1922-1937.

35. Feldman, M.P.; Florida, R. The Geographic Sources of Innovation: Technological Infrastructure and Product Innovation in the United States. Ann. Assoc. Am. Geogr. 1994, 84, 210-229. [CrossRef]

36. Jaffe, A.; Trajtenberg, M.; Henderson, R. Geographic localization of knowledge spillovers as evidenced by patent citations. Q. J. Econ. 1993, 108, 577-598. [CrossRef]

37. Acs, Z.J.; Anselin, L.; Varga, A. Patents and innovation counts as measures of regional production of new knowledge. Res. Policy 2002, 31, 1069-1085. [CrossRef]

38. Cassi, L.; Plunket, A. Research collaboration in co-inventor networks: Combining closure, bridging and proximities. Reg. Stud. 2015, 49, 936-954. [CrossRef]

39. Ter Wal, A.L. Cluster emergence and network evolution: A longitudinal analysis of the inventor network in Sophia-Antipolis. Reg. Stud. 2013, 47, 651-668. [CrossRef]

40. Scherngell, T.; Hu, Y. Collaborative knowledge production in China: Regional evidence from a gravity model approach. Reg. Stud. 2011, 45, 755-772. [CrossRef]

41. Huallacháin, B.Ó.; Lee, D.S. Urban centers and networks of co-invention in American biotechnology. Ann. Reg. Sci. 2014, 52, 799-823. [CrossRef]

42. Zhang, Z.; Li, Z.F.; Yang, X. The micro-scale spatial features of innovative activities in Shanghai, China: A research based on the patent data. Mod. Urban Res. 2018, 5, 80-85.

43. Liu, J. Lectures on Whole Network Approach: A Practical Guide to Ucinet; Gezhi Press: Shanghai, China, 2009.

(C) 2019 by the authors. Licensee MDPI, Basel, Switzerland. This article is an open access article distributed under the terms and conditions of the Creative Commons Attribution (CC BY) license (http://creativecommons.org/licenses/by/4.0/). 